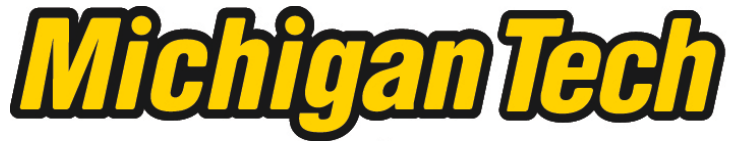 \\ Michigan Technological University Create the Future Digital Commons @ Michigan Tech
}

\section{Information integration and management through the design and construction phases of a project life cycle}

Christopher T. Brokaw

Michigan Technological University

Follow this and additional works at: https://digitalcommons.mtu.edu/etds

Part of the Civil and Environmental Engineering Commons

Copyright 2012 Christopher T. Brokaw

\section{Recommended Citation}

Brokaw, Christopher T., "Information integration and management through the design and construction phases of a project life cycle", Master's report, Michigan Technological University, 2012.

https://doi.org/10.37099/mtu.dc.etds/509

Follow this and additional works at: https://digitalcommons.mtu.edu/etds

3 Part of the Civil and Environmental Engineering Commons 
INFORMATION INTEGRATION AND MANAGEMENT THROUGH THE DESIGN AND CONSTRUCTION PHASES OF A PROJECT LIFE CYCLE

\author{
By \\ Christopher T. Brokaw

\begin{abstract}
A REPORT
Submitted in partial fulfillment of the requirements for the degree of MASTER OF SCIENCE CIVIL ENGINEERING
\end{abstract}

MICHIGAN TECHNOLOGICAL UNIVERSITY

2012

(C) 2012 Christopher T. Brokaw 
This report, "INFORMATION INTEGRATION AND MANAGEMENT THROUGH THE DESIGN AND CONSTRUCTION PHASES OF A PROJECT LIFE CYCLE," is hereby approved in partial fulfillment of the requirements for the Degree of MASTER OF SCIENCE IN CIVIL ENGINEERING.

Civil and Environmental Engineering

Signatures:

Report Advisor

Dr. Amlan Mukherjee

Committee Member

Dr. Kris Mattila

Committee Member

Dr. Nilufer Onder

Department Chair

Dr. David Hand

Date 


\section{Table of Contents}

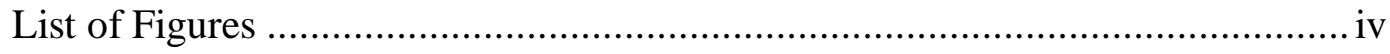

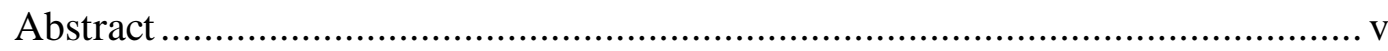

1. Introduction .................................................................................. 1

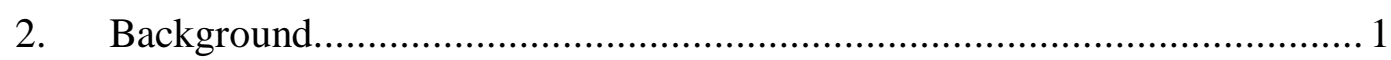

3. Ecosystems and the Ecology of Practice ............................................. 2

4. Interaction of Actors with Technology ............................................ 3

5. Information Supply Chain ............................................................. 6

6. Building Information Modeling......................................................... 6

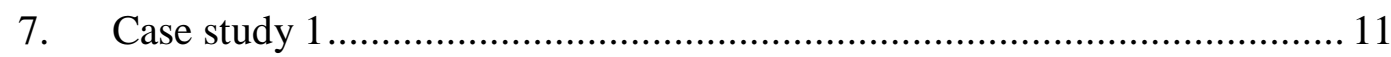

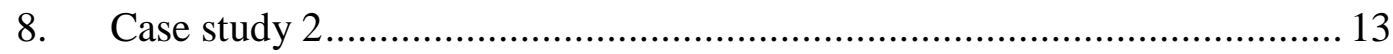

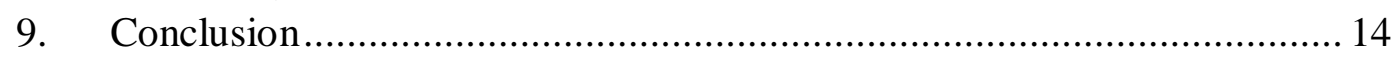

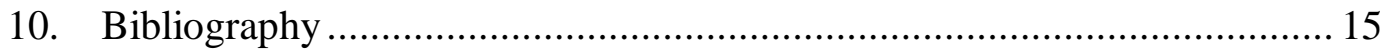




\section{List of Figures}

Figure 1: Information Flow through the Project .................................................

Figure 2: Information Supply Chain ....................................................................6

Figure 3: Example of BIM and 3D Model, Autodesk Revit ................................... 7

Figure 4: Structural Framing Schedule, Autodesk Revit .......................................8

Figure 5: Integration of A Schedule With A 3D Model, Autodesk Navisworks .........9

Figure 6: Partially Complete Simulation of Construction, Autodesk Navisworks ......9

Figure 7: Example of Clash Detective, Autodesk Navisworks............................... 10

Figure 8: Detailed View of Beam Elements, Autodesk Revit .................................11

Figure 9: Diagram of Actors in Case Study ....................................................... 12

Figure 10: Information Supply Chain of Case Study ........................................... 13 


\section{Abstract}

Information management is a key aspect of successful construction projects. Having inaccurate measurements and conflicting data can lead to costly mistakes, and vague quantities can ruin estimates and schedules. Building information modeling (BIM) augments a 3D model with a wide variety of information, which reduces many sources of error and can detect conflicts before they occur. Because new technology is often more complex, it can be difficult to effectively integrate it with existing business practices.

In this paper, we will answer two questions: How can BIM add value to construction projects? and What lessons can be learned from other companies that use BIM or other similar technology? Previous research focused on the technology as if it were simply a tool, observing problems that occurred while integrating new technology into existing practices. Our research instead looks at the flow of information through a company and its network, seeing all the actors as part of an ecosystem. Building upon this idea, we proposed the metaphor of an information supply chain to illustrate how BIM can add value to a construction project. This paper then concludes with two case studies. The first case study illustrates a failure in the flow of information that could have prevented by using BIM. The second case study profiles a leading design firm that has used BIM products for many years and shows the real benefits of using this program. 


\section{Introduction}

"Building information modeling (BIM) is a digital representation of physical and functional characteristics of a facility. A BIM is a shared knowledge resource for information about a facility forming a reliable basis for decisions during its life-cycle..." (bSa). This allows for improved information management and project control when compared to projects designed with $2 \mathrm{D}$ drafting software. The primary benefit is that the digital model includes significantly more information about the project, and can be easily distributed to all interested parties, increasing the information flow across the network. Despite the many advantages of upgrading to new technology, many companies have had problems integrating this new technology into existing business practices. There has been extensive research that investigated what causes these problems.

In this paper, we will expand upon the concept of an "ecology of practice" (Harty and Whyte 2010) to explore the "ecosystem" populated by technology, decision makers, and information producers. Within this ecosystem, the project participants and the information are part of a coupled system, and an imbalance in one area can lead to costly mistakes. In addition, we will use the metaphor of the supply chain to trace the flow of information between the actors. This "information supply chain" will highlight where the actors add value to the project as it progresses from an idea to completion. Within this framework, we discuss the use of integrative platforms such as Navisworks to maintain balance, and examine a case study to support and illustrate the above construct.

\section{Background}

Integrating new software like BIM into existing business practices is rarely quick or easy. Technology does not exist alone, but as part of an "ecology of practice" (Harty and Whyte 2010). While it may be tempting to believe that new software will automatically improve business, steep learning curves and incompatible business practices are barriers that obstruct smooth implementation and prevent organizations from taking full advantage of the software capabilities. Many of these barriers, like conflicts between a scope and business obligations (Dossick and Neff 2010), are not new or unique to BIM projects but are inherent to the construction industry and business organizations. Progressive companies with inspired leadership can overcome some of these barriers by encouraging teamwork and collaboration 
for the benefit of the project. Harty and Whyte (2010) noticed that when companies tried to switch to a new technology, the staff looked for ways to preserve some of the old practices because of their knowledge and familiarity, resulting in emergent hybrid combinations of two ecologies. Sometimes, these practices can be inefficient and cause the staff to do more work, while in other cases they preserve analog processes that are more effective than their digital equivalents (Whyte 2011). One common location for these hybrid practices is at the interface between the software and users. Dossick and Neff (2011) observed: "BIM excels at helping people find problems, but does not support the dialogue needed to solve many problems encountered in complex design and construction projects." This is because computer models are often seen as "clean" objects, while brainstorming ideas and troubleshooting are relatively "messy" processes. The messy talk can be encouraged by reducing the formality of meetings and using analog ways of brainstorming and then transferring those ideas into the model.

While a company can benefit greatly from using BIM, they operate within networks of architects, contractors, and suppliers, so it is mutually advantageous if all the companies on a project use compatible BIM programs. Taylor (2007) identified numerous antecedents that led to successful implementation of 3D CAD software, both within the company and across the network. He went on to show that many companies evolve in a predictable manner as they gain experience with BIM; they integrate it further into their processes and encourage its spread across their networks (Taylor and Bernstein 2009). This was described as a series of paradigms that most of the companies experienced: visualization, coordination, analysis, and supply chain integration.

Using these studies as a point of departure, the objective of this research is illustrate the flow of information through a project, and the problems that can arise when the balance is upset within the ecosystem.

\section{Ecosystems and the Ecology of Practice}

Construction projects exist within an ecosystem wherein technology, decision makers, and information producers coexist, their interactions focused on creating, sharing, and consuming information. If the balance is upset, if information is incorrect or missing, it can lead to costly mistakes. 
In most construction projects, the major actors are the owner, architect/engineer, general contractor (or construction manager), subcontractors, and suppliers. In some delivery systems, a single company may perform the duties of multiple actors (for example, the $\mathrm{A} / \mathrm{E}$ and $\mathrm{GC}$ in a Design-Build project). While construction is typically seen as a linear process, there are feedback loops associated with value engineering, revisions, and troubleshooting, which can involve one or more of the actors accessing and changing the same information in parallel. This means that all of the involved companies, to some extent, create, share, and consume information during a project, and each company has decision makers and information producers. This intertwined flow of information makes it imperative that all the actors receive the information they need, have the correct tools to do their part of the project, and pass along the correct information to the next step in the project (Figure 1). In other words, the ecosystem is in balance when all the parties coexist in harmony, supported by technological platforms.

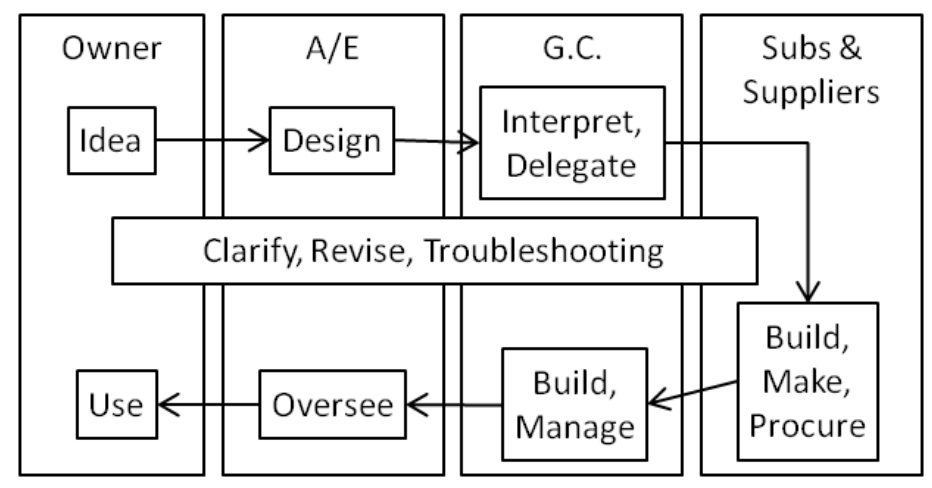

Figure 1: Information Flow through the Project

Since BIM and similar programs have been around for many years, there have been numerous opportunities for research to be conducted on these early adopters. This research has revealed many problems that fit into our "ecosystem" analogy and can be attributed to conflicts between technology, decision makers, or information producers.

\section{Interaction of Actors with Technology}

One problem inherent to any large project is the problem of ever-changing documents. It is imperative that all of the actors know which version is the newest, what recent changes are included in this version, and that it was distributed to all interested parties. Digital document management (DM) systems are an ideal platform to solve this 
problem because it removes the limitations of physical documents and allows files to be compiled in a central location, updated, and shared electronically. However, this relies on robust and user-friendly software. The management on one project discovered that the DM system was slow, complex, and inefficient. As a result the staff avoided using it when possible, and instead used paper copies, e-mail, and floppy disks - practices that the DM system was trying to replace (Harty and Whyte 2010). The management plugged and patched these loopholes in an attempt to force the staff to use the DM system, but because of the poor software and inadequate training, the staff was working less efficiently. This vignette illustrates shortcomings in both technology and decision makers within this ecosystem.

When a company implements a new technology, employees with the appropriate skills will be scarce and in high demand until training catches up with implementation. One such company had problems when they augmented their 2D CAD processes with 3D CAD (Whyte 2011). Each team of designers had a single 3D modeler and a few 2D CAD drafters. The 3D modeler would extract 2D views from the 3D model, and then the $2 \mathrm{D}$ drafters would add the details to finish each drawing. The 3D modeler would also incorporate their team's work into the shared model. This was intended to give them ownership of their model, but also created a bottleneck and extra work over an entirely 2D process. Any changes, instead of being updated directly in the 2D model, had to be made in the 3D model, then output as 2D drawings, which then had to have the details re-applied. This slowed down the process significantly, but promised long-term benefits of increased coordination and reduced errors, so it was seen as being "worth it in the end." This problem was caused by a poor utilization of assets (in this case information producers), which is part of learning how to effectively and efficiently implement a new technology.

One of the main themes of BIM is collaboration and the ability to seamlessly share information. Instead of paper plans, the model can now be displayed on a screen during a presentation, or shared over the internet during a conference call. Even though BIM can create models that are incredibly detailed and full of information, research has shown that using BIM often end up restraining creativity and leaving the project with suboptimal solutions (Dossick and Neff 2011). "BIM excels at helping people find problems, but does not support the dialogue needed to solve many problems encountered in complex design and 
construction projects." Large meetings, conference calls, and presentations tend to feel more formal, passive, and inflexible, which is the exact opposite of environments that promote creativity. The model appears to be perfect and clean, and researchers found that the staff often had difficulty finding solutions by looking at the screen, but found it much easier after sketching on a whiteboard, or in after-meeting conversations. One solution would to find a hybrid combination of these digital and analog activities. There are digital whiteboards that can interface with a computer and act like a large touch-screen. The model can be projected onto the whiteboard, allowing the staff to sketch directly on the model, and the best ideas can be incorporated into the model afterwards.

Another part of the problem that restricts creativity is the amount of documentation used during large projects. The formality of a "paper trail" tends to restrict the free flow of ideas, as a minor change may not be seen as important enough to be worth the effort. This is exacerbated by the organizational structure of modern companies, where it is quite common for paperwork being sent from one company to another to have to travel up a chain of command, be sent to the other company, and then travel down the other chain of command to the intended recipient. This is also seen during meetings with representatives from the various parties, where they may have the knowledge and skill to suggest improvements, but not the authority. In these situations, the creative process is interrupted as they seek approval from higher, ruining the momentum and the feeling of team cohesion.

This research showed that creativity is an informal, active, and flexible process, but is often hampered by the fundamental differences in how the technology and the decision makers process information. Even with the latest and greatest technology, it is beneficial to incorporate non-digital artifacts and informal team meetings to encourage creativity.

This idea of hybrid practices was seen in other similar research. Harty and Whyte (2010) observed a roof contractor whose designers, in addition to using 3D modeling software, still created physical models of the roof. They found that it was easier to see and understand what it actually looked like, and easier to show the design to other people, like management or the client. They also created models at multiple scales to show various amounts of detail at different stages of the design process. In another situation, design staff found it easier and more intuitive to work off of paper plans. 


\section{Information Supply Chain}

As a project progresses through the design and construction phases, the actors create information that adds value to the project. The information supply chain is a tool for visualizing how each actor contributes value to the project, shown in Figure 2. This also shows that BIM (along with other software) can add value in every major activity of the project. For this project, Autodesk Revit and Navisworks were used to illustrate the key components of BIM and how they add value to the project.

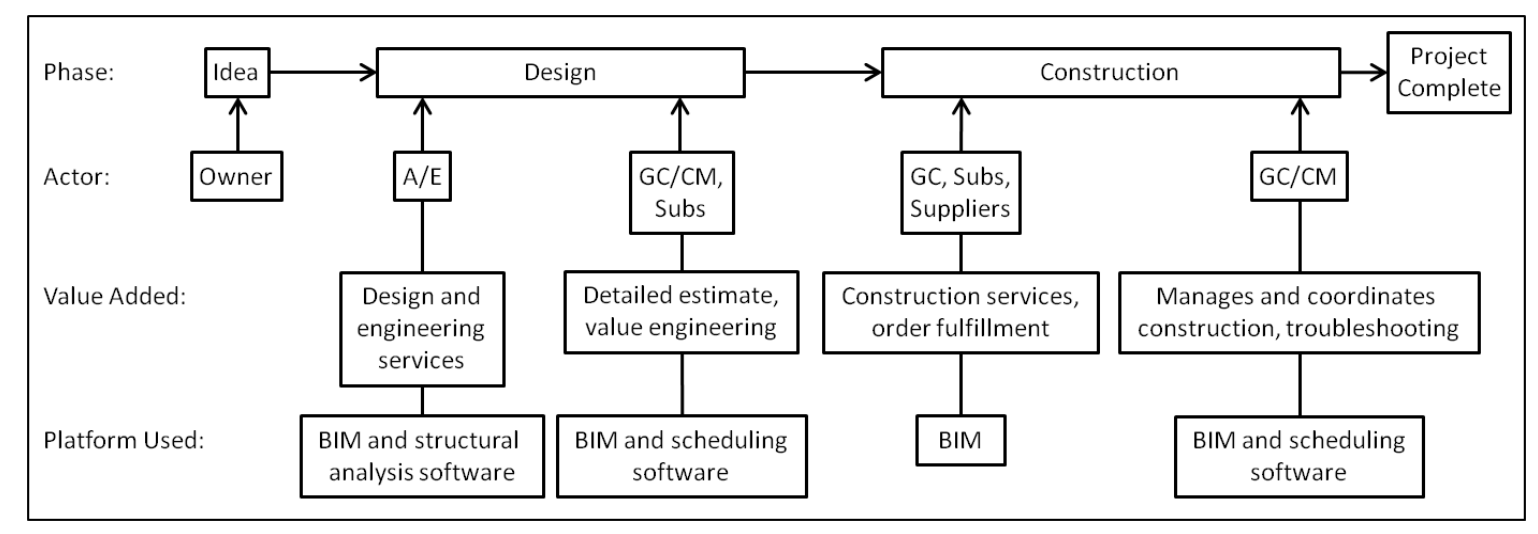

Figure 2: Information Supply Chain

\section{Building Information Modeling}

There have been many programs that allow designers to create 3D illustrations, but what separates BIM from 3D CAD is that it creates an actual model of the project. The software knows what each element is, its size, location in 3D space, and many other parameters associated with each element. This allows for a lot more information to be passed between the actors, leading to more accurate plans, fewer problems, and increased productivity.

The architect and engineer add value to the project by turning the owner's ideas into drawings while trying to meet design criteria. Figure 3 shows a 3D model of a simple steel building in Autodesk Revit. By modeling it in 3D, it is easier to show the client the overall look of the project, and can include architectural features and landscaping.

Since this is a single 3D model, any changes will automatically be visible in any 2D views. This saves a lot of work compared to $2 \mathrm{D}$ plans and reduces errors associated with 
updating the other views. On the left side of Figure 3 are views of the floors and elevations that can be converted into sheets and exported as $2 \mathrm{D}$ plans.

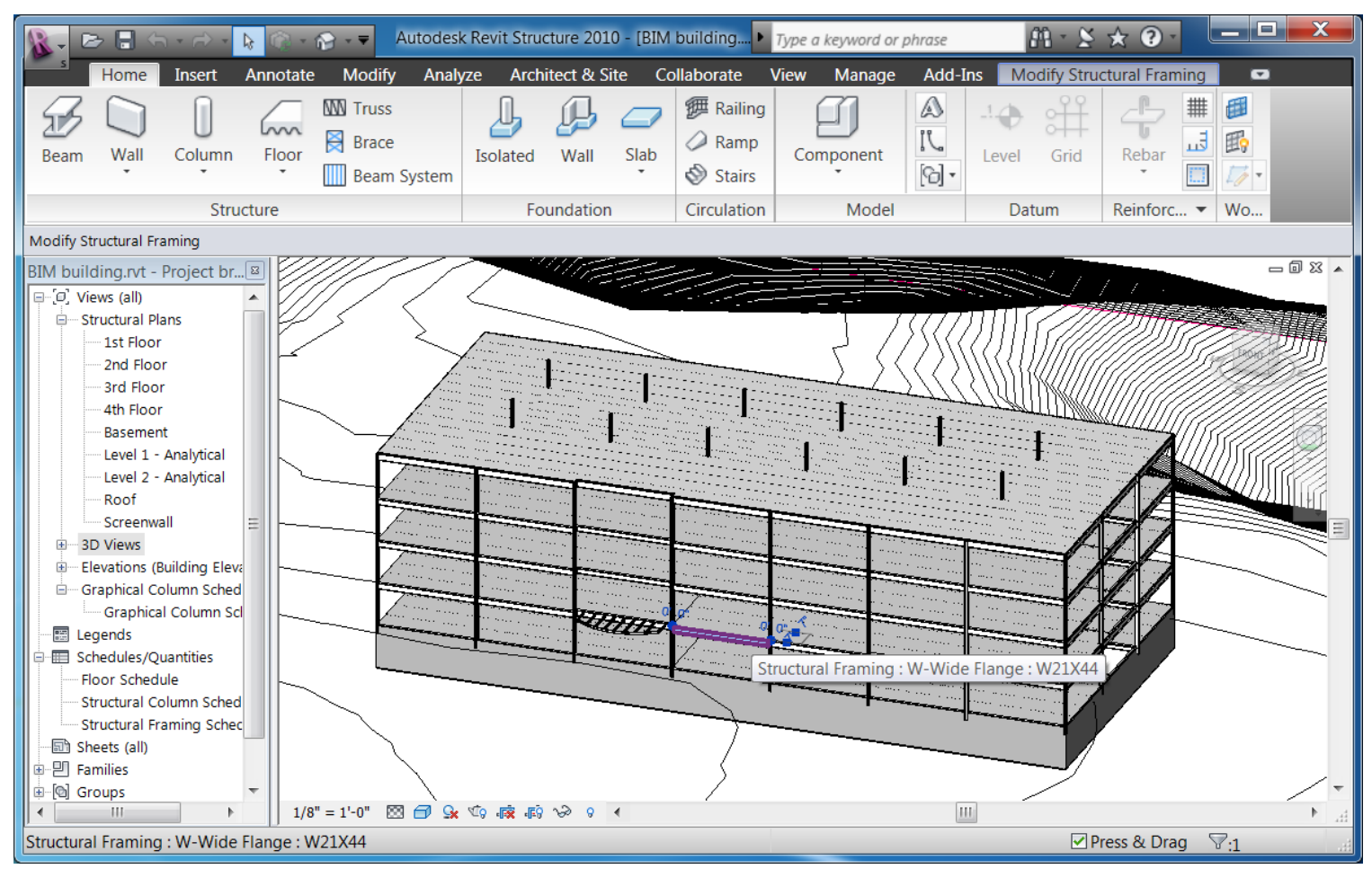

Figure 3: Example of BIM and 3D Model, Autodesk Revit

The model also allows architects and engineers to create multiple versions of the same project and "play around" with different ideas. Each version can be easily evaluated on various criteria by using tools within the program and other common software, allowing the designer to optimize the project early in the design process.

The contractors add value to the project by constructing the project for the lowest cost, saving the owner money. The accuracy of the contractor's bid relies upon an accurate estimate and quantity takeoff. Since a BIM program can keep track of every element in the project, it is very easy to create quantity takeoffs and schedules, as shown in Figure 4. The unit cost can be input for each type of element, and a total cost calculated. This data can be exported to spreadsheet software and integrated into estimates. The schedule can also be broken down by phase, floor, or any other attribute to create more detailed estimates. 


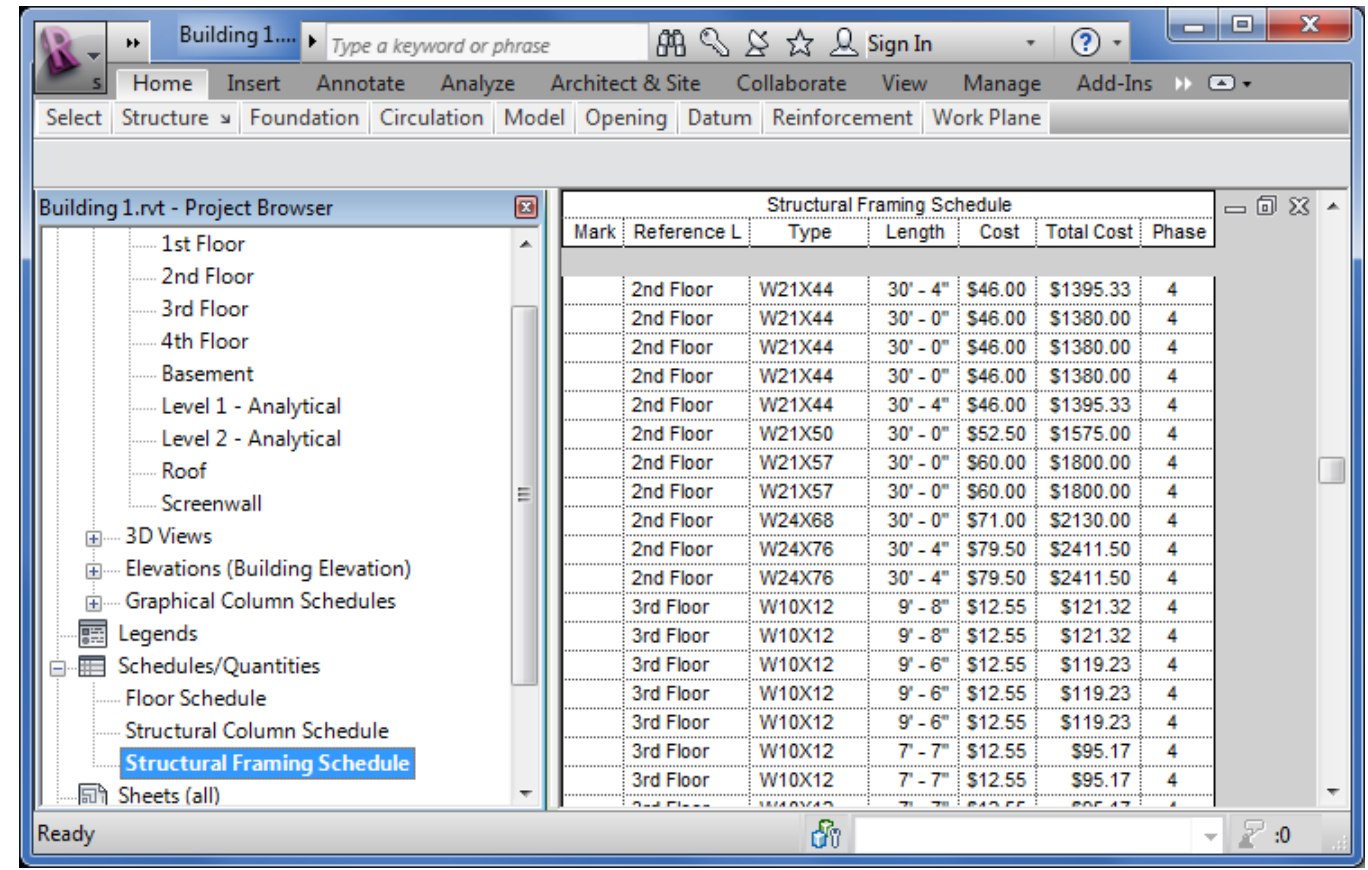

Figure 4: Structural Framing Schedule, Autodesk Revit

Because of the large amounts of detail, there is opportunity to integrate the model with the supply chain. For example, the supplier could provide models of their products, complete with detailed information like part number, dimensions, options, etc, allowing the engineer to pick the exact part and have it integrate directly with the model. Similarly, the designer can send the entire model to the supplier, where the quantity takeoffs can tell them exactly what to make. Both examples can add value to the project by removing guesswork and increasing productivity.

By incorporating information about the phasing and construction sequence, some BIM programs can create an animation of the project, often called 4D modeling ("time" is the $4^{\text {th }}$ dimension). This adds value to the project by allowing for better control of the jobsite and better understanding of the sequence of activities in both time and space. Figure 5 shows the 3D model and a simplified Gantt chart of the project in Autodesk Navisworks. Each activity is associated with certain elements of the project, and can include demolition and construction activities. The schedule was made in a dedicated scheduling program which can take into account relationships between activities, resource limitations, and working schedules (Microsoft Project). Figure 6 shows day 14 of the simulation, along with the activities that are occurring at that time. Transparent blue objects are under construction, solid objects are complete. 


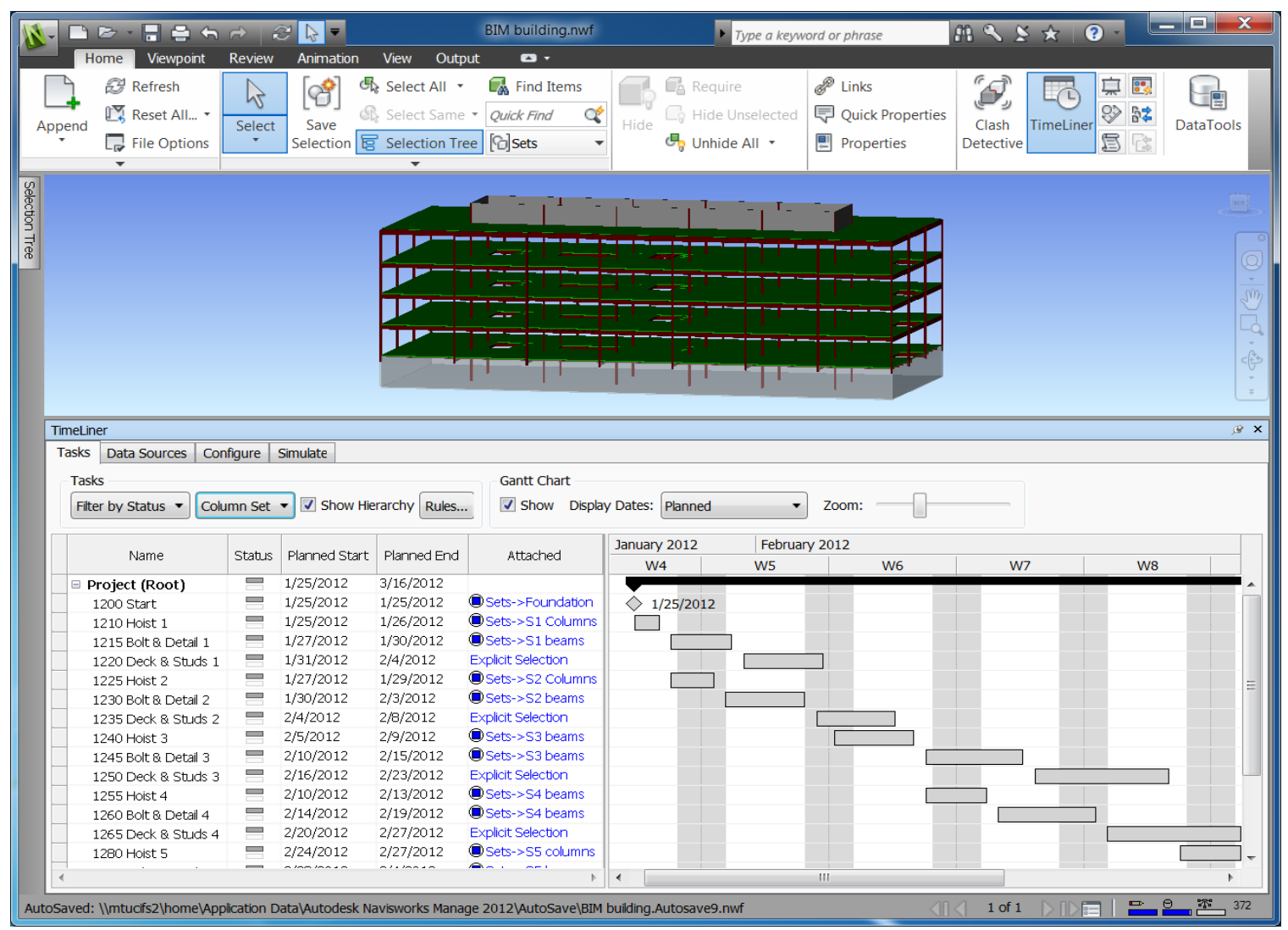

Figure 5: Integration of A Schedule With A 3D Model, Autodesk Navisworks

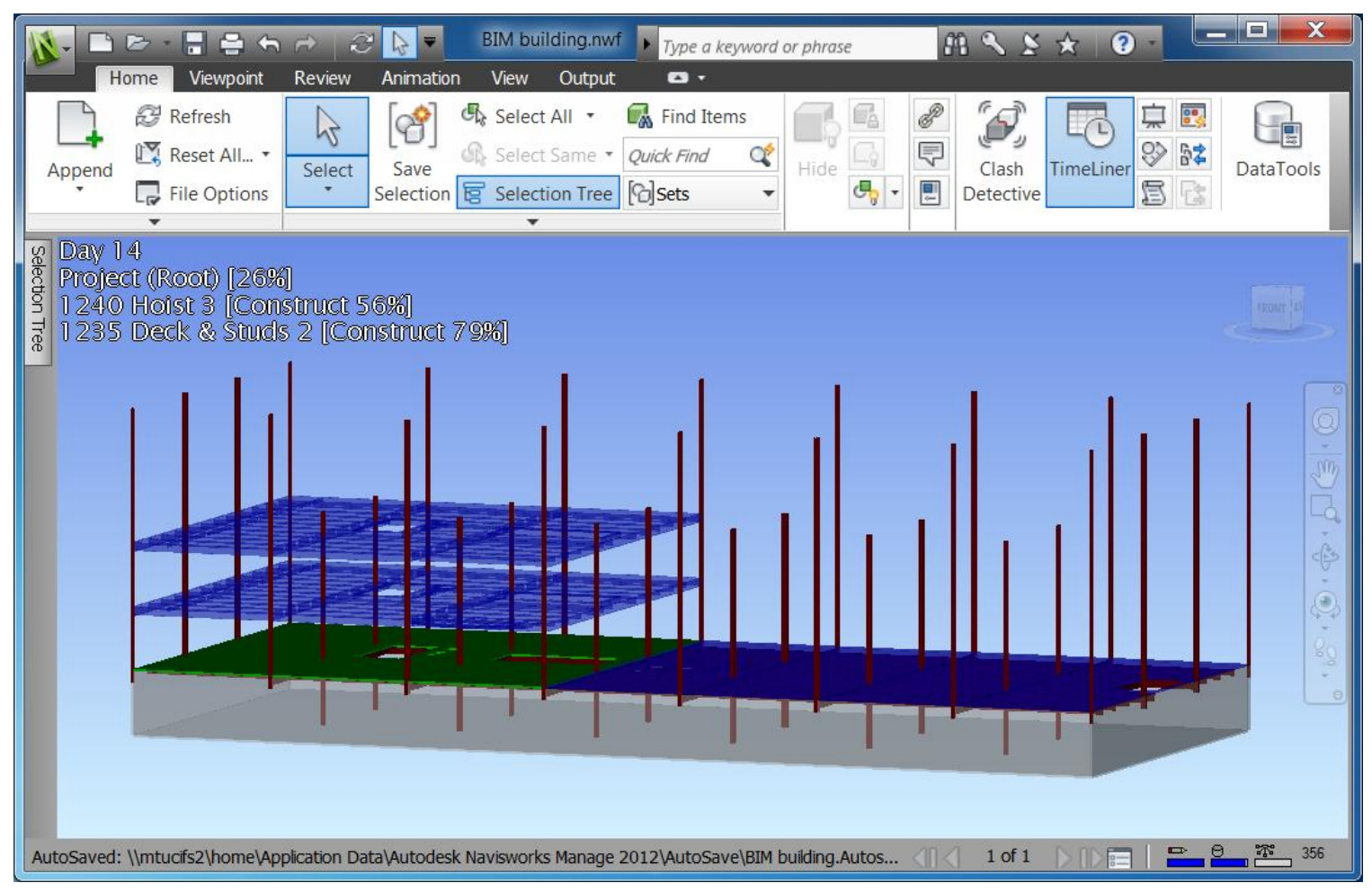

Figure 6: Partially Complete Simulation of Construction, Autodesk Navisworks 
Another powerful tool in BIM is its ability to integrate 3D models from the other programs into a complete model of the project. Since the software knows the size, shape, and location of each object, it can detect conflicts between objects trying to occupy the same space (for example, plumbing and HVAC ducts). This allows the engineer and contractors to make sure everything fits within the space allotted, and resolve any conflicts before construction even starts. Conflicts can also be the result of mistakes made by the user, possibly caused by inexperience or incorrect assumptions. Figure 7 shows the "clash detective" feature in Navisworks and two beams that intersect. This adds value during the detailed design phases when the subcontractors' work is integrated into the model, detecting problems before they occur.

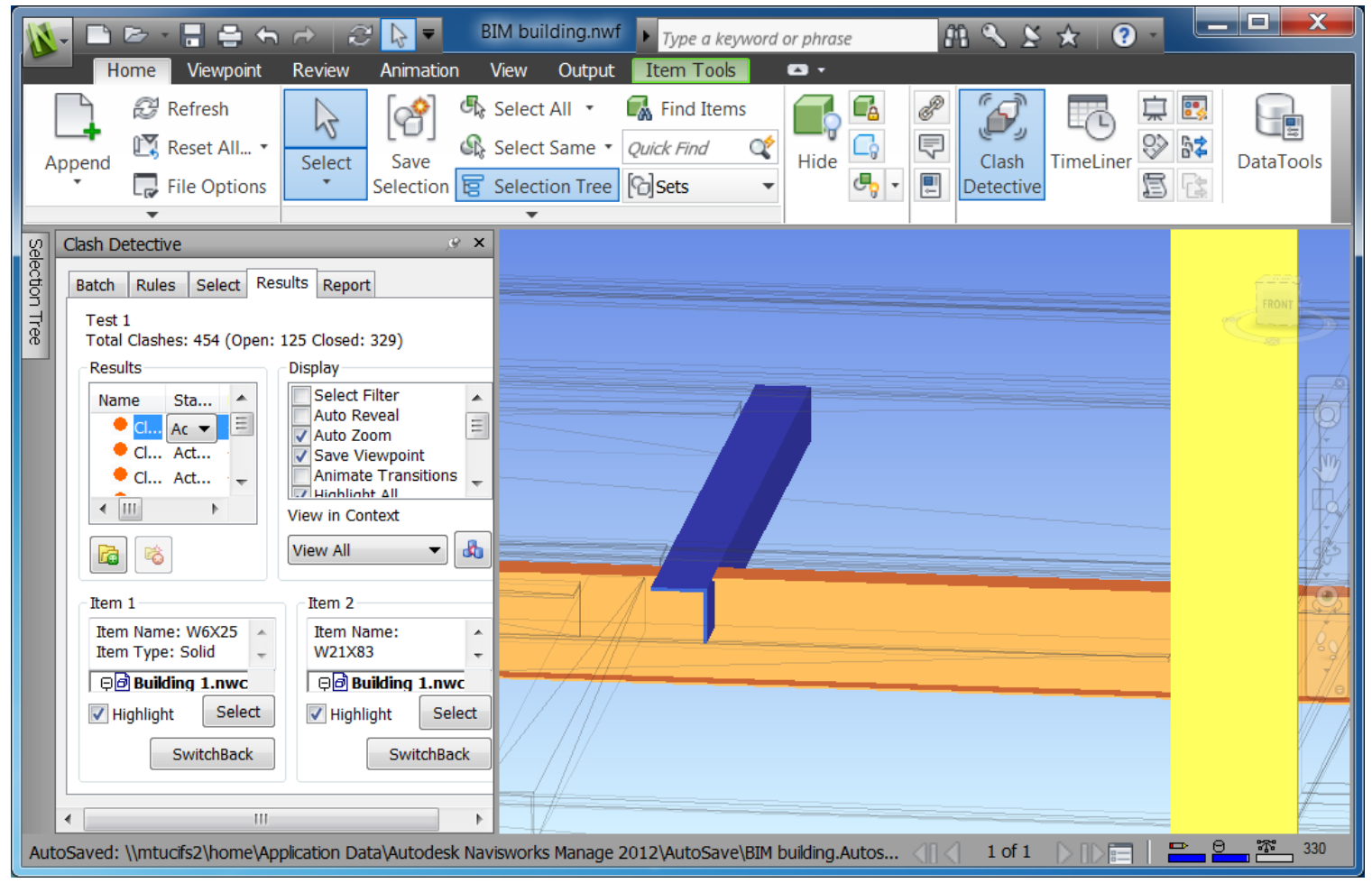

Figure 7: Example of Clash Detective, Autodesk Navisworks

One advantage of BIM is that the entire model is a single digital file. This makes distribution and version management significantly easier than physical paper plans. Within BIM software, the model can be centrally located and each employee can update it as they work, allowing all parties to have the latest version. It can even monitor areas of the project that are important to each party and warn them when changes are made in those areas. BIM 
adds value to the project by increasing information flow, keeping all parties updated with the most recent model, and detecting problems before they occur.

$\mathrm{BIM}$ is also a useful tool during construction, where it can be used on the jobsite for reference and troubleshooting purposes. Whenever a problem arises, instead of consulting paper plans with a limited amount of detail, the model can show every detail of the project with exact dimensions, including relationships with different objects, as shown in Figure 8. This adds value by enabling the workers and contractors to answer many of their own questions and quickly find solutions, instead of asking for clarification and waiting for an answer.

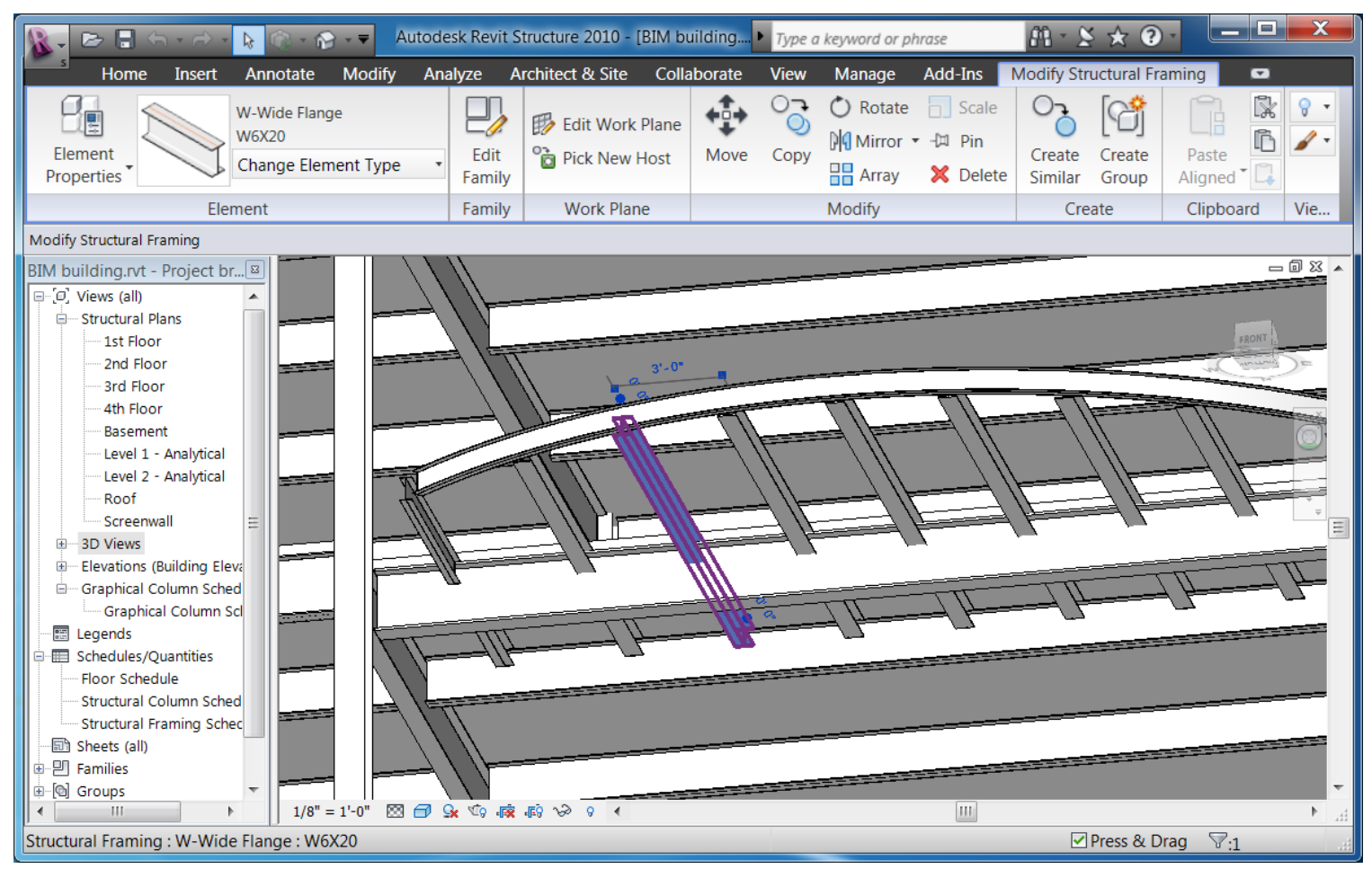

Figure 8: Detailed View of Beam Elements, Autodesk Revit

\section{Case study 1}

This case study was taken from Sweet \& Shneier's Legal Aspects of Architecture, Engineering and the Construction Process.

In the early 1990's, Broward County, FL wanted to widen a portion of a road and replace a bridge. The designs prepared by Frederic R. Harris, Inc., and the contract was awarded to Triple $\mathrm{R}$ Paving. Triple $\mathrm{R}$ and the county value engineered the project and 
decided to build a bridge with one span instead of two spans to save money. Triple $\mathrm{R}$ hired Joe Roles to redesign the bridge, based on the original design from Harris. The actors in this case study and their relationships are shown in Figure 9.

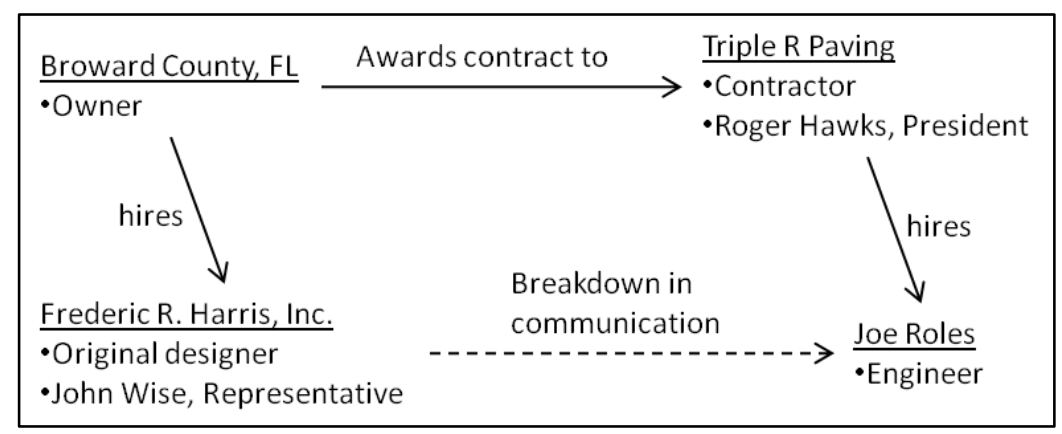

Figure 9: Diagram of Actors in Case Study

During construction, it was discovered that there were sight distance problems caused by the horizontal geometry. This halted construction on the bridge, which was left unfinished while they searched for a solution. Triple $\mathrm{R}$ was able to continue working on other sections of the road, but it was at a much slower pace due to traffic problems.

Joe Roles testified that he did not check the horizontal sight distance because his design did not change any of the horizontal geometry from the original design. According to Roger Hawks, president of Triple R, John Wise, Harris's representative, knew that there might be a problem with the sight distance and agreed to personally check the design against the standards, but failed to mention it at any meetings during the design process.

Another delay occurred on a different portion of the project which included a detention pond designed to drain into a nearby canal. On the plans drawn up by Harris, the canal's elevation was incorrect; in reality its elevation was higher than the proposed elevation of the pond, which would cause the retention pond to not function properly.

The project was eventually completed behind schedule, after which Triple R sued and was awarded over $\$ 110,000$ for damages. Harris tried to defend themselves with the "no damages for delay" clause, but lost because the delay was caused by their mistakes that they should have caught and corrected. Since they did not, this was seen to be in bad faith.

This vignette highlights the importance of having correct, relevant, and accurate information. The details are not available as to exactly why Harris did not check the horizontal sight distances or the canal elevation, so any solution is mere speculation. But we can still learn lessons from this case that can be applied to other situations. Generally 
speaking, the failure was caused by an "information producer" that did not double-check their data or the site conditions, and did not pass along a warning to the information users that there might be a problem with the sight distance. This breakdown in information flow cost the major actors a lot of time, effort, and money. The information supply chain for this project is diagramed in Figure 10.

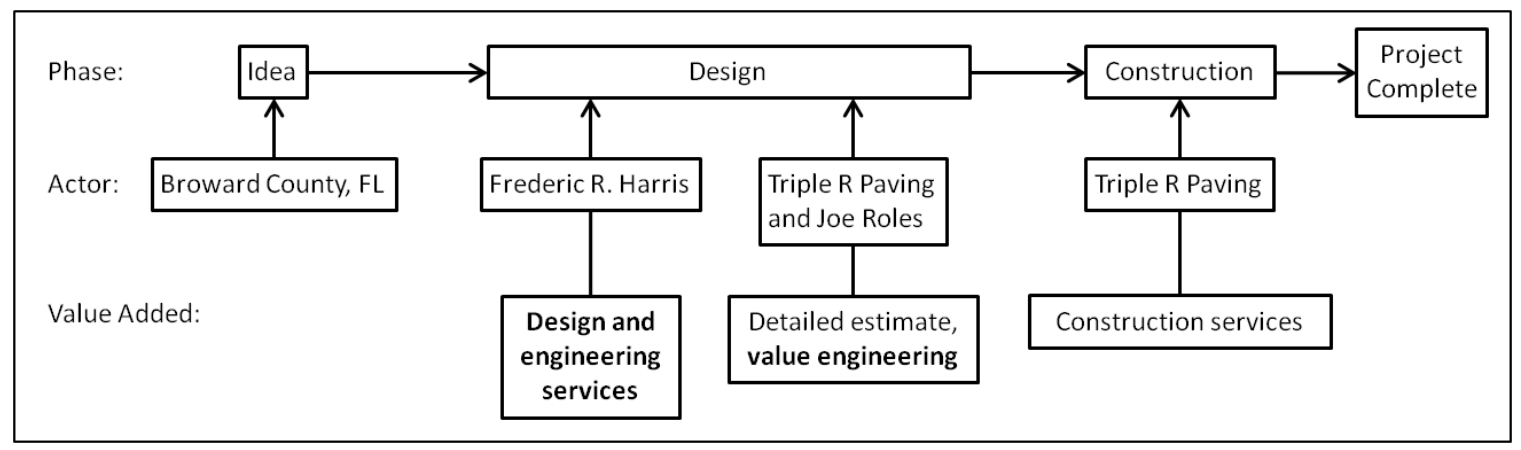

Figure 10: Information Supply Chain of Case Study

Modern design software has the ability to automate many routine calculations and incorporate design criteria which can alert an engineer to many problems. This could have allowed Joe Roles to catch the mistake as he was redesigning the bridge, or possibly prevent Harris from making the mistake in the first place. Since BIM has the ability to incorporate site data into the model, it could make it easier to spot problems like the canal elevation during the design process.

\section{Case study 2}

When BIM is used to its full potential by an experienced company, the results can be quite impressive. Mortenson Construction of Minneapolis, MN, has used Autodesk Revit and Navisworks for many years on projects both large and small. One project was the Research Complex 2 for the University of Colorado, where Mortenson served as the general contractor. This project was built alongside Research Complex 1, which used traditional methods, allowing for comparisons of the two techniques. A major difference was that Mortenson was able to use BIM to identify problems during the design phase and ask many RFI's early in the process, resulting in 74\% fewer RFI's asked during construction of the foundations and $47 \%$ fewer during steel erection (Mortenson). This was estimated to save $\$ 585,000$ in administration costs (Autodesk). It is difficult to accurately quantify the benefits 
of using BIM, since it would include the cost of mistakes that never happened. One observable benefit is the lack of delays and increased productivity. Mortenson completed RC2 two months ahead of schedule and six months ahead of RC1. On another project, they observed that their production rate of sheer walls was increased by $26 \%$ and the project finished 6 weeks ahead of schedule.

\section{Conclusion}

BIM is a very powerful program, and can provide many advantages during a construction project. Because of the differences between new technology and established practices, there often arise problems, both on the individual level, business level, and across the project network. By looking at the project as if it were an ecosystem, it becomes easier to see where the problems occur, and that new technology works best when the ecosystem is working in harmony. Within this ecosystem, the flow of information identifies where value is added to the project. This idea can be expanded using the metaphor of an information supply chain, which highlights the actors that use BIM to add value at specific points within the project. By focusing on incorporating BIM into these activities, companies can significantly improve productivity, reduce the chance of mistakes, and realize significant savings of both time and cost. 


\section{Bibliography}

Autodesk. [internet]. Customer Stories - Mortenson Construction. Available from: http://images.autodesk.com/adsk/files/navisworks10_custstory_mortenson_final.pdf

buildingSMART alliance. [internet]. National Institute of Building Sciences. bSa NBIMS FAQ. Available from: http://www.buildingsmartalliance.org/index.php/nbims/faq/

Dossick, C. S., and Neff, G. (2010). Organizational Divisions in BIM-Enabled Commercial Construction. Journal of Construction Engineering and Management, 136(4), 459467.

Dossick, C. S., and Neff, G. (2011). Messy talk and clean technology: communication, problem-solving and collaboration using Building Information Modelling. Engineering Project Organization Journal, 1(2), 83-93.

Harty, C., and Whyte, J. (2010). Emerging Hybrid Practices in Construction Design Work: Role of Mixed Media. Journal of Construction Engineering and Management, 136(4), 468-476.

Mortenson Construction. [internet]. Examples of Commercial Construcion Projects. Available from: http://www.mortenson.com/resources/images/11320.pdf

Sweet, J., \& Schneier, M. M. (2004). Legal Aspects of Architecture, Engineering and the Construction Process. Nelson, Toronto, Ontario.

Taylor, J. E. (2007). Antecedents of Successful Three-Dimensional Computer-Aided Design Implementation in Design and Construction Networks. Journal of Construction Engineering and Management, 133(12), 993-1002.

Taylor, J. E., and Bernstein, P. G. (2009). Paradigm Trajectories of Building Information Modeling Practice in Project Networks. Journal of Management in Engineering, 25(2), 69-76.

Whyte, J. (2011). Managing digital coordination of design: emerging hybrid practices in an institutionalized project setting. Engineering Project Organization Journal, 1(3), 159-168. 